\title{
DESAIN ALAT MONITORING BEBAN GARDU DISTRIBUSI SECARA REAL TIME MENGGUNAKAN METODE PERANCANGAN PRODUK DI PT . PLN (Persero) RAYON BAGUALA
}

\author{
M. L. Pattiapon \\ Program Studi Teknik Industri, Fakultas Teknik Universitas Pattimura, Ambon \\ A. Soleman \\ Program Studi Teknik Industri, Fakultas Teknik Universitas Pattimura, Ambon \\ Muhammad Faisal Darmawan \\ PLN Wilayah Maluku dan Maluku Utara, Ambon
}

\begin{abstract}
ABSTRAK
Penelitian ini membahas desain alat monitoring beban gardu distribusi. Alat ini dibuat bekerja secara real time untuk mengurangi potensi kesalahan, serta dapat memonitoring beban gardu setiap jam yang sebelumnya dilakukan oleh manusia yang hanya memonitoring beban gardu tiga bulan sekali. Dalam penelitian ini agar alat dapat bekerja secara real time meliputi, pengukuran arus dan tegangan menggunakan sensor, memilih sistem akuisisi data sebagai jembatan untuk menghubungkan mengirimkan hasil pengukuran ke komputer dan membuat program untuk menampilkan hasil pengukuran pada komputer. Untuk mengukur arus dan tegangan menggunakan sensor ACS712 dan sensor tegangan ZMPT101B. Sistem akuisisi data yang digunakan adalah Arduino Mega 2560, kemudian untuk menampilkan hasil pengukuran pada komputer yang dilakukan oleh sensor arus dan tegangan adalah menggunakan program Graphical User Interfacing (GUI) MATLAB. Pada GUI MATLAB dibuat untuk menampilkan beberapa variabel yang menjadi indikator kondisi gardu yang dimulai dari tegangan gardu, arus gardu, beban gardu hingga persentase beban gardu yang dicuplik setiap satu jam. Uji kinerja alat telah dilakukan untuk memonitoring beban pada gardu BGLWHR2008 yang terletak di Rayon Baguala antara pukul 17:00 hingga pukul 23:00. Proses monitoring dibagi berdasarkan waktu yaitu sebelum jam pemakaian puncak yaitu pukul 17:00 - 19:00, pemakaian beban pucak antara pukul 19:00 - 21:00 dan setelah waktu puncak antara pukul 21:00 - 23:00. Dari hasil monitoring dapat dilihat antar pukul 19:00 - 21:00 pemakaian beban gardu mencapai 55,90 \% lebih tinggi $5 \%$ sebelum sebelum waktu jam puncak. Alat ini telah mampu memantau beban gardu dimana hasilnya hampir sama dengan pengukuran yang dilakukan oleh manusia.
\end{abstract}

Kata Kunci: Gardu Distribusi, Beban listrik, PT. PLN (Persero) Rayon Baguala

\begin{abstract}
This study discusses the design of a tool to monitor a load of the distribution substation. This tool is made to real time operation to reduce errors and to monitor substation load every hour that previously done by humans who only monitor every three months. It works by measuring current and voltage using sensors, choosing a data acquisition system as a bridge to connect sending measurement results to a computer and creating a program to display the measurement results on a computer. The sensors used are the ACS712 and ZMPT101B voltage sensor. The data acquisition system uses Arduino Mega 2560 where MATLAB Graphical User Interfacing (GUI) program is utilized to display the results of measurements on a computer. MATLAB GUI is made to display several variables that are indicators of substation conditions starting from substation voltage, substation current, substation load up to the percentage of substation load that is sampled every hour. Tool performance tests have been carried out to monitor the load on the BGLWHR2008 substation located in Rayon Baguala between 17:00 and 23:00. The monitoring process is divided based on time, namely before peak use hours, which are 17:00 - 19:00, peak load usage between 19:00 - 21:00 and after peak time between 21:00 - 23:00. Results show that the use of substation loads reaches 55.90\% 5\% higher between 19:00 - 21:00 before peak hours. This tool has been able to monitor the load of substations where the results are almost the same as measurements made by humans.
\end{abstract}

Keywords: Distribution Substation, Electrical Load, PT. PLN (Persero) Rayon Baguala 


\section{PENDAHULUAN}

PT. PLN (Persero) merupakan perusahaan yang mengelola tentang ketenagalistrikan di Indonesia dituntut untuk memberikan pelayanan yang prima terhadap pelanggan dan implementasi K3 dalam setiap lingkup pekerjaan.

Sistem distribusi pada PT . PLN (Persero) merupakan salah satu sistem dalam tenaga listrik yang mempunyai peran penting karena berhubungan langsung dengan konsumsi energi listrik, terutama pemakai energi listrik tegangan menengah dan tegangan rendah.

Dalam jaringan distribusi, salah satu peralatan yang penting adalah Gardu Trafo Tiang (GTT). Alat yang berperan penting pada GTT yang dimaksud disini adalah trafo, karena trafo pada GTT berfungsi untuk mentransformasikan energi listrik yaitu menurunkan tegangan dari $20 \mathrm{kV}$ ke $400 \mathrm{~V}$.

Untuk menjaga aset trafo maka dibutuhkan monitoring secara real time agar fluktuasi beban suatu trafo dapat diketahui sehingga dapat diketahui kondisi pembebanan trafo dalam kondisi normal atau overload.

Selama ini di PT.PLN (Persero ) Area Ambon, monitoring pembebanan trafo hanya dilakukan tiga bulan sekali, sehingga rawan akan tidak terpantaunya beban lebih. Pada semester 2 tahun 2015 di PT.PLN (Persero ) Area Ambon Rayon Baguala telah terjadi 5 kali gangguan trafo. Hal ini bisa diakibatkan karena tidak termonitornya pembebanan trafo secara real time.

Dalam implementasi pengukuran arus dan tegangan gardu distribusi, alat yang digunakan petugas pelayanan teknik adalah tang ampere. Hal ini menunjukkan bahwa pemantauan beban gardu masih dilakukan secara manual atau tidak secara real time, hasil pemantauan tidak terekam setiap saat sehingga hasil fluktuasi beban pada trafo tidak terlihat.

Hal ini melatarbelakangi penulis untuk membuat suatu perangkat atau alat yang mampu menginformasikan kondisi beban gardu distribusi secara real time, dan pengamat hanya memantau kondisi beban gardu distribusi dari komputer secara real time.

Adapun tujuan penelitian ini adalah agar dapat mengidentifikasi kebutuhan user terkait pengukuran beban gardu distribusi dan agar dapat merancang alat monitoring beban gardu secara real time

\section{LANDASAN TEORI}

\section{Gardu Distribusi Tenaga Listrik dan Trafo Arus}

Gardu distribusi tenaga listrik adalah suatu bangunan gardu listrik yang dipasok dengan tegangan menengah $20 \mathrm{kV}$ dari saluran kabel tegangan menengah atau saluran udara tegangan menengah. Gardu distribusi atau terdiri dari instalasi perlengkapan hubung bagi tegangan menengah (PHB - TM), transformator distribusi dan perlengkapan hubung bagi tegangan rendah (PHB-TR) untuk memasok kebutuhan tenaga listrik bagi para pelanggan baik dengan tegangan menengah (TM $20 \mathrm{kV}$ ) maupun tegangan rendah $(380 / 220)$.

Pada gardu ditribusi juga terdapat trafo arus yaitu sebagai trafo yang berfungsi sebagai alat bantu untuk pengukuran arus dengan nilai besar yang dihasilkan oleh transformator distribusi pada bagian tegangan rendah di sisi primer atau disebut arus primer $\left(I_{P}\right)$ diturunkan pada sisi sekunder atau disebut arus sekunder $\left(I_{S}\right)$. Perbandingan transformasi arus ( k) dapat dituliskan dengan persamaan 2.1 dibawah ini:

$$
(k)=\frac{l p}{l_{S}}
$$

Sedangkan untuk menentukan besar arus pada sisi sekunder adalah:

$$
I_{s}=\frac{I p}{k}
$$

Penelitian ini dilakukan pada gardu distribusi BGLWHR2008 yang terletak di Waitatiri Baguala. Gardu ini termasuk gardu distribusi yang memiliki kapasitas sebesar 160.000 VA. Dalam gardu tersebut memiliki trafo arus dengan perbandingan antara sisi primer dan sekunder adalah $300 / 5$. Untuk mengetahui besar arus sekunder dari trafo arus yang terdapat di dalam gardu BGLWHR2008 dapat dituliskan dengan persamaan 2.3 dibawah ini:

$$
I_{s}=\left(\frac{5}{300} \times I_{P}\right)
$$

Beban sebuah gardu distribusi merupakan besarnya pemakaian arus dan tegangan. Untuk menghitung besarnya beban gardu distribusi ( 3 fasa) yang di supply ke para pemakai atau konsumen yaitu menggunakan persaman 2.4 dibawah ini:

$$
\text { beban }=\sqrt{3} \times 400 \times \bar{I}
$$


Dimana $\bar{I}$ adalah arus rata-rata yang dihasilkan oleh masing-masing fasa. Satuan beban sendiri adalah volt-Ampere (VA). Sedangkan untuk menghitung persentase beban pada gardu yaitu menggunakan persamaan 2.5 dibawah ini:

$$
\% \text { beban }=\frac{\text { Eeban }}{\text { kapasitas gardu }} \times 100 \%
$$

1. Gardu Beton

Gardu Beton adalah gardu distribusi yang bangunan pelindungnya terbuat dari beton (campuran pasir, batu dan semen). Gardu beton termasuk `gardu jenis pasangan dalam, karena pada umumnya semua peralatan penghubung/pemutus, pemisah dan trafo distribusi terletak di dalam bangunan beton. Dalam pembangunannya semua peralatan tersebut di disain dan diinstalasi di lokasi sesuai dengan ukuran bangunan gardu. memperlihatkan sebuah gardu distribusi konstruksi beton.

2. Gardu Metal Clad /Besi

Gardu distribusi yang bangunan pelindungnya terbuat dari besi. Gardu besi termasuk gardu jenis pasangan dalam, karena pada umumnya semua peralatan penghubung/pemutus, pemisah dan trafo distribusi terletak di dalam bangunan besi. Semua peralatan tersebut sudah di instalasi di dalam bangunan besi, sehingga dalam pembangunannya pelaksana pekerjaan tinggal menyiapkan pondasinya saja.

3. Gardu Portal

Gardu portal adalah gardu listrik tipe terbuka (outdoor) yang memakai konstruksi tiang/menara kedudukan transformator minimal 3 meter diatas platform. Perlengkapan peralatan terdiri atas fuse cut out, arrester lighting, transformer, satu lemari PHB tegangan rendah maksimal 4 jurusan, isolator tumpu atau gantung dan sistem pentanahan.

4. Gardu Cantol

Gardu cantol adalah tipe gardu listrik dengan transformator yang dicantolkan pada tiang listrik besamya kekuatan tiang minimal 500 dan instalasi gardu dapat berupa 1 cut out fised, 1 lighting arrester dan 1 panel PHB tegangan rendah dengan 2 jurusan atau transformator completely self protected (CSP Transformator).

\section{Transformator}

Transformator adalah suatu alat listrik yang dapat memindahkan dan mengubah energi listrik dari satu atau lebih rangkaian listrik ke rangkaian listrik yang lain melalui suatu gandengan magnet dan berdasarkan prinsip induksi - electromagnet.

\section{Arduino Mega 2560}

Arduino adalah pengembangan dari mikrokontroller yang berbasis arduino menggunakan chip Atmega 2560 (Gambar 2.6). Arduino sebagai jembatan untuk menghubungkan antar perangkat keras dengan perangkat lunak. Arduino mega 2560 memiliki pin I/O cukup banyak sejumlah 54 buah digital I/O pin (15 pin diantaranya adalah PWM), 16 pin masukan analog yang terhubung dengan analog to digital converter (ADC) dengan resolusi sebesar 10 bit, 4 pin UART (serial port hardware). Arduino ini dilengkapi sebuah osilator sebagai pembangkit frekuensi $16 \mathrm{MHz}$, sebuah port USB, power jack DC, ICSP menghubungkan power dari USB ke PC dan tegangan operasi sebesar $5 \mathrm{~V}_{\mathrm{DC}}$.

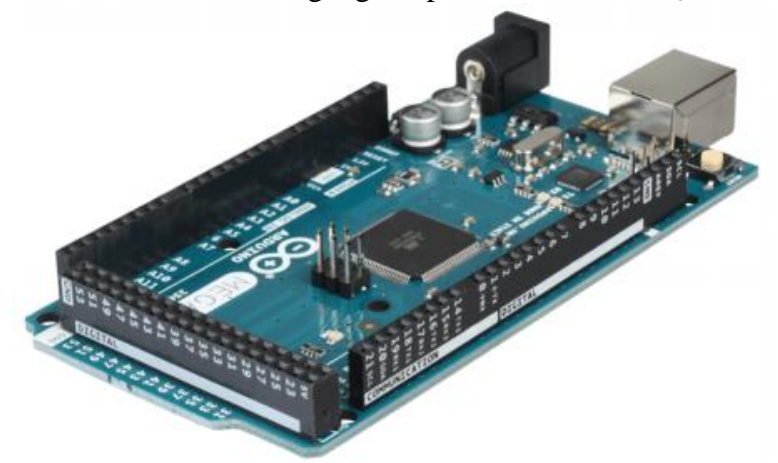

Arduino Mega 2560

\section{Sensor Arus ACS712}

Sensor ACS712 adalah sensor arus untuk mengukur jenis arus AC. Dari gambar 2.7, keluaran dari sensor ACS712 adalah tegangan DC. Tegangan operasi sensor ini adalah sebesar $5 \mathrm{~V}_{\mathrm{DC}}$ dan memiliki 
tingkat sensivitas antara 66 s/d $200 \mathrm{mV} / \mathrm{A}$. Berdasarkan data sheet sensor, arus maksimum yang mampu melewati sensor ini adalah sebesar 5 A.

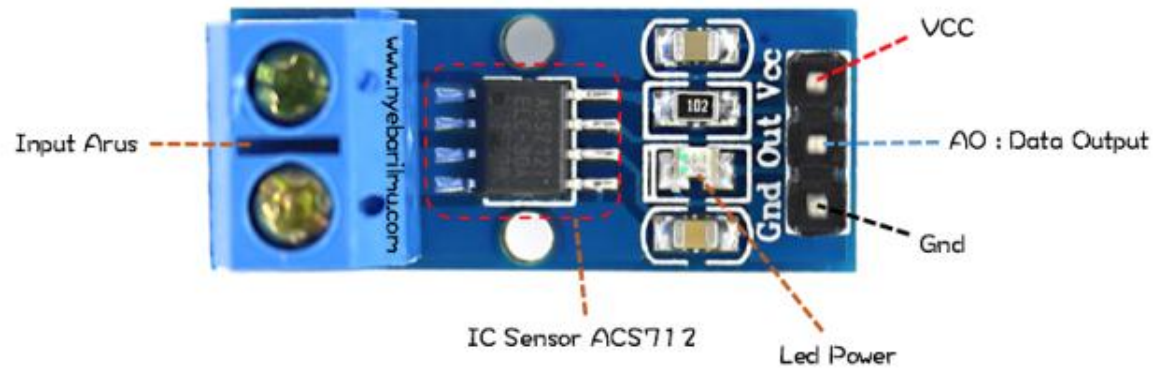

Sensor Arus ACS712

\section{Sensor ZMPT101B}

Sensor tegangan ZMPT101B merupakan sensor tegangan yang mengukur tegangan AC hingga mencapai 1000 VRMS. Tegangan operasi sensor ini adalah sebesar 5 VDC, dan menghasilkan tegangan keluaran adalah tegangan DC. Sensor ZMPT101B perlu dikalibrasi antara tegangan masukan AC dengan tegangan keluaran sensor DC. Karakteristik atau fungsi transfer dari sensor ZMPT101B adalah berbentuk kurva linear.

\section{Desain Produk}

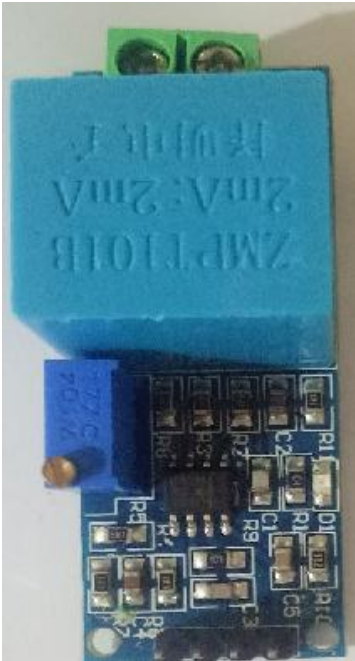

Sensor ZMPT101B

. Desain merupakan suatu proses yang dapat dikatakan telah seumur dengan keberadaan manusia di bumi. Hal ini sering tidak kita sadari (Irvan M, 2015). Akibatnya, sebagian dari kita berpendapat seolaholah desain baru dikenal sejak zaman modern dan merupakan bagian dari kehidupan modern. Dalam bahasa sehari-hari kata desain sering diartikan sebagai sebuah perancangan, rencana atau gagasan. Dalam kamus besar Bahasa Indonesia dikatakan bahwa desain sepadan dengan kata perancangan . Jika istilah desain maknanya rencana, maka rencana adalah bendanya (benda yang dihasilkan dalam proses perencanaan). Kegiatannya disebut merencana, pelaksananya disebut perencanaan, sedangkan segala sesuatu yang berkaitan erat dengan proses pelaksanaan pembuatan suatu rencana disebut perencanaan. Jadi kata mendesain mempunyai pengertian yang secara umum setara dengan merencana, merancang, rancang bangun atau merekayasa.

Desain produk adalah salah satu aktivitas yang merancang suatu bentuk kemudian diproses melalui proses produksi dan hasil akhirnya menjadi suatu barang atau produk yang dihasilkan dari proses produksi tersebut serta nilai dan kegunaanya dapat memenuhi keinginan konsumen yang disesuaikan dengan perkembangan zaman dan waktu yang berubah-ubah. Desain produk juga merupakan suatu profesi yang kegiatannya berkaitan dengan suatu proses inovasi teknologi. 


\section{Produk}

Menurut Agus Ahyari produk merupakan sebagai hasil dan kegiatan produksi akan mempunyai wujud tertentu, mempunyai sifat fisik dan kimia tertentu. Disamping itu akan datang tenggang waktu antara saat diproduksi dengan saat dikonsumsi (Ahyari, 1985: 8). Karl T. Ulrich mendefinisikan produk sebagai sesuatu yang dijual oleh perusahaan kepada pembeli (Ufrich, 2001:2).

Proses

Proses adalah merupakan urutan langkah - langkah pengubahan sekumpulan output . Proses pengembangan produk adalah urutan langkah - langkah atau kegiatan - kegiatan dimana suatu perusahaan berusaha untuk, menyusun, merancang dan mengkomersilkan suatu produk. Proses Pengembangan produk yang umum terdiri dari enam tahap.Proses ini diawali dengan suatu fase perencanaan, yang berkaitan dengan kegiatan - kegiatan pengembangan teknologi dan penelitian tingkat lanjut.

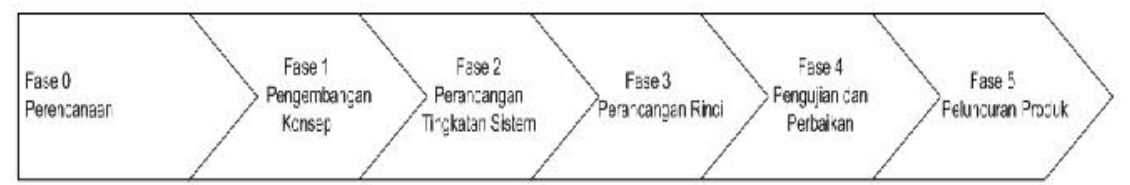

Proses Pengembangan Produk

\section{Proses Perancangan}

Perancangan system produksi diawali dengan merancang produk yang akan diproduksi. Hasil keputusan desain produk selanjutnya ditransmisikan ke operasi sebagai spesifikasi produksi, dan spesifikasi produksi merumuskan karakteristik produk dan memungkinkan pelaksanaan produksi. Desain merupakan hal yang sangat penting bagi kelangsungan hidup perusahaan. Berbagai desain produk baru diciptakan karena orang percaya bahwa ada kebutuhan akan produk tersebut. Kemajuan teknologi berdampak pada desain-desain produk yang secara terus menerus mengalami perkembangan pesat. Sebagian besar perusahaan secara kontinyu melakukan perubahan, perbaikan dan pengembangan terhadap produk- produk lama yang telah usang dan ketinggalan jaman. Dalam hal ini dibutuhkan perancangan produk yang mempunyai kepekaan dan ide-ide baru yang dapat terus dikembangkan.

\section{Proses Perancangan Produk}

Pokok - pokok dalam proses perancangan produk dapat dijelaskan sebagai berikut. Konsep perancangan merupakan tahap awal dari proses produksi yang berkaitan dengan pengembangan ide - ide, yang dapat dikembangkan dari pasar yang sudah ada atau dari teknologi yang sudah ada, hanya saja tidak semua ide tersebut dapat dikembangkan menjadi suatu produk baru (Ginting, 2010). Ide - ide untuk mengembangkan suatu produk dapat dikembangkan bila memenuhi beberapa pengujian atau analisis, antara lain potensi pasar, kelayakan dari segi keuangan, dan kesesuaian operasi. Konsep perancangan disetujui maka selanjutnya dilakukan perancangan sebuah prototipe yang kemudian dilanjutkan dengan pembuatan prototipe dan proses pengembangannya. Prototipe merupakan bentuk tiruan yang menyerupai produk akhirnya. Prototipe yang dibuat kemudian dilakukan pengujian baik pengujian pasar maupun pengujian terhadap penampilan teknis produk. Jika pengujian telah memenuhi syarat selanjutnya dilakukan.

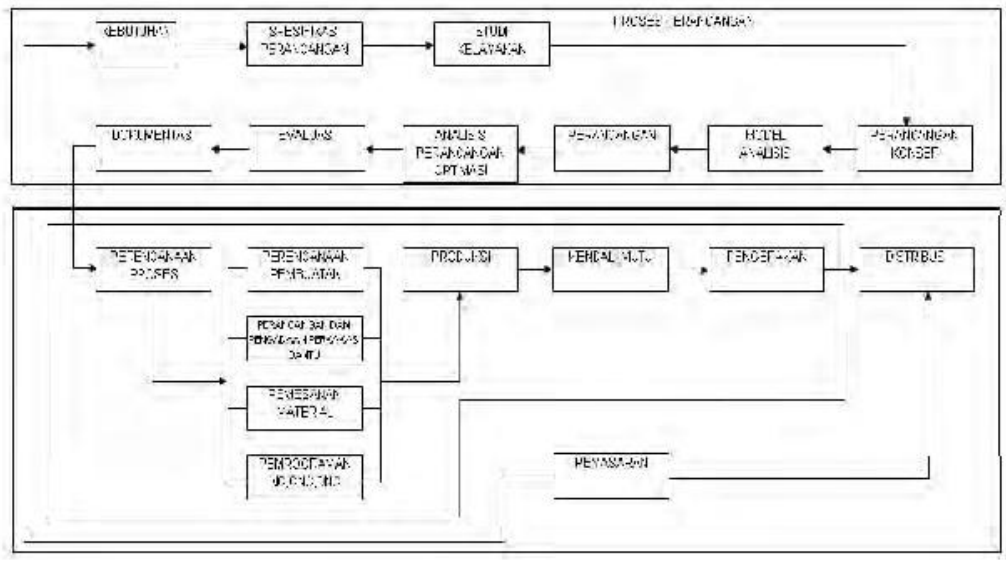

Diagram Alir Proses Perancangan dan Pembuatan 


\section{METODE PENELITIAN}

\section{Variabel dan Definisi Operasional}

Variabel keputusan dapat dinotasikan dengan lambang X. Yang termasuk dalam indikator variabel keputusan dalam penilitian adalah sebagai berikut :

a. Tegangan $\left(\mathrm{X}_{1}\right)$

b. Volt $\left(\mathrm{X}_{2}\right)$

Variabel keputusan merupakan suatu indikator untuk mencapai variabel tujuan. Yang mana variabel tujuan adalah untuk mengetahui daya beban gardu.

\section{Tahapan Penelitian Analisa Data}

Penelitian ini dilaksanakan melalui beberapa tahap yaitu :

1. Survey Lapangan

Survey lapangan diperlukan guna meneliti lebih lanjut apa yang akan menjadi permasalahan dalam penelitian.

2. Studi Pustaka

Kegiatan ini dilakukan untuk menelusuri konsep-konsep teoritis yang relevan dengan masalah penelitian dan sekaligus untuk mengetahui data, metode pengumpulan data dan metode analisis yang tepat dalam menyelesaikan permasalahan penelitian tersebut.

3. Perumusan Masalah dan Tujuan Penelitian

Hasil studi pendahuluan dianalisis untuk menentukan masalah utama yang dipilih sebagai masalah penelitian. Selanjutnya, ditetapkan tujuan penelitian untuk mengarahkan semua aktivitas dalam kegiatan penelitian, termasuk pengumpulan data dan analisis.

4. Pembahasan

Pada tahap ini beberapa fase pengembangan diimplementasikan diantaranya

A. Perencanaan

B. Dalam fase ini diidentifikasi peluang masalah pada pola kerja di lingkungan PT. PLN (Persero) Rayon Baguala terutama dalam sisi pekerjaan pengukuran beban. Sehingga dari identifikasi tersebut bisa berlanjut pada fase pengembangan konsep.

C. Pengembangan Konsep

Pada fase pengembangan konsep para pelaku / petugas pelaksana pekerjaan dalam hal ini adalah petugas yantek PT PLN (Persero ) Rayon Baguala dimintai keterangan terkait permasalahan pekerjaan berupa pengisian kuisioner terkait pekerjaan pengukuran beban gardu distribusi.

D. Perancangan Tingkatan Sistem

Fase perancangan tingkatan sistem menterjemahkan tindak lanjut fase pengembangan konsep dari hasil pengisian kuisioner yang telah diberikan kepada petugas yantek PT PLN (Persero) Rayon Baguala menjadi rancangan bentuk alat monitoring beban gardu distribusi secara real time.

E. Perancangan Detail

Setelah fase perancangan tingkatan sistem dijalani maka dibuatlah spesifikasi - spesifikasi produk / komponen penyusun alat monitoring beban gardu distribusi secara real time

F. Pengujian

Dalam fase ini dilakukan pengujian dan hasil pengukurannya kemudian dipindahkan ke table agar dapat dianalisa terkait nilai pembebanan gardu distribusi tiap beberapa periode

5. Analisa Data

Data yang telah dikumpulkan selanjutnya diolah dan diintrepretasikan untuk menjawab tujuan penelitian. Pada tahap ini digunakan metode perancangan produk.

6. Kesimpulan dan Saran

Hasil pengolahan dan analisis data kemudian disimpulkan dengan memperhatikan tujuan penelitian. Disamping itu, juga diberikan saran yang berkaitan dengan penggunaan / penerapan hasil penelitian

\section{HASIL DAN PEMBAHASAN}

\section{Deskripsi Produk}

Alat monitoring beban gardu secara real time adalah alat yang digunakan untuk memantau beban gardu distribusi secara real time tanpa melibatkan manusia. Sehingga dengan adanya alat ini dapat membantu kinerja PT PLN (Persero) dalam rangka pemantauan asset khususnya gardu distribusi

\section{Alur Pengukuran Beban Gardu Distribusi}

Pengukuran beban gardu distribusi dilaksanakan setiap tiga bulan sekali. Berikut urutan pelaksanaan pengukuran beban gardu distribusi. 
1. Admin teknik mencetak blangko pengukuran untuk masing-masing tim pengukuran berdasarkan rutenya

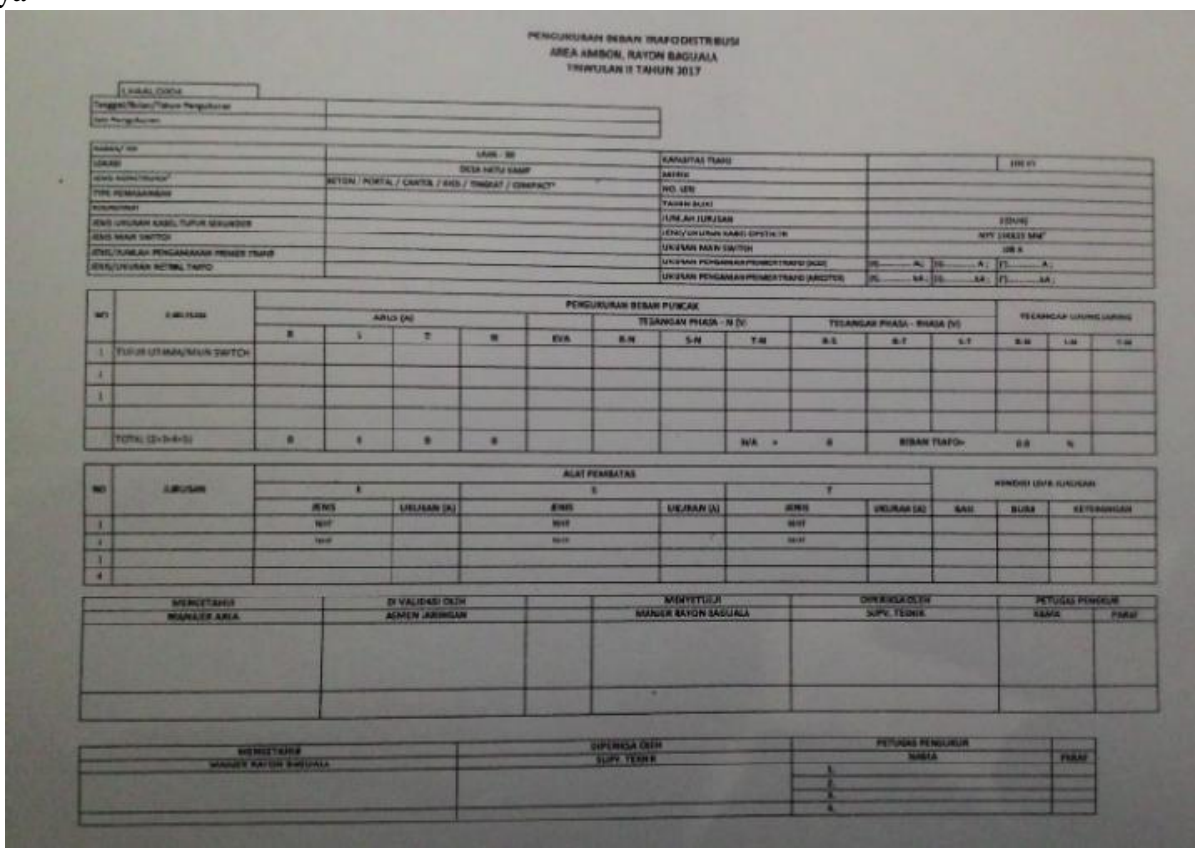

Blangko Pengukuran Gardu Distribusi

2. Petugas mulai melakukan pengukuran beban gardu distribusi pada masing - masing rute yang sudah di tentukan dengan menggunakan alat tang ampere.

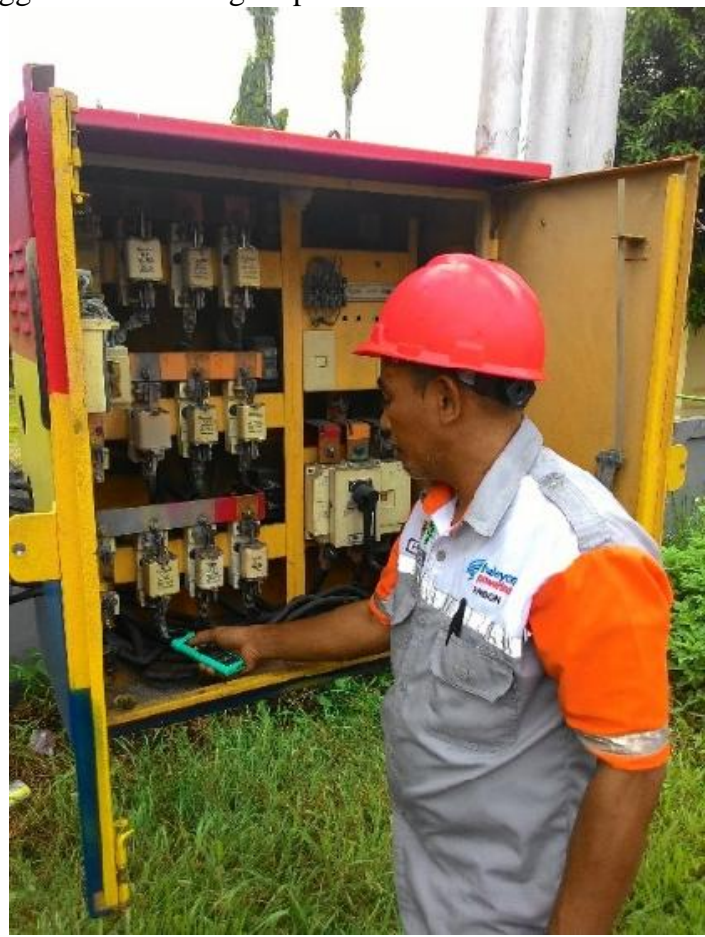

Pengukuran Gardu Distribusi

3. Setelah selesai melakukan pengukuran. Petugas mengisi hasil pengukuran di blangko pengukuran dan mengumpulkan ke admin teknik.

4. Admin teknik berkoordinasi dengan pegawai bagian teknik di PLN Rayon untuk melakukan perekapan hasil ukur di aplikasi managemen trafo dan software Microsoft excel. 


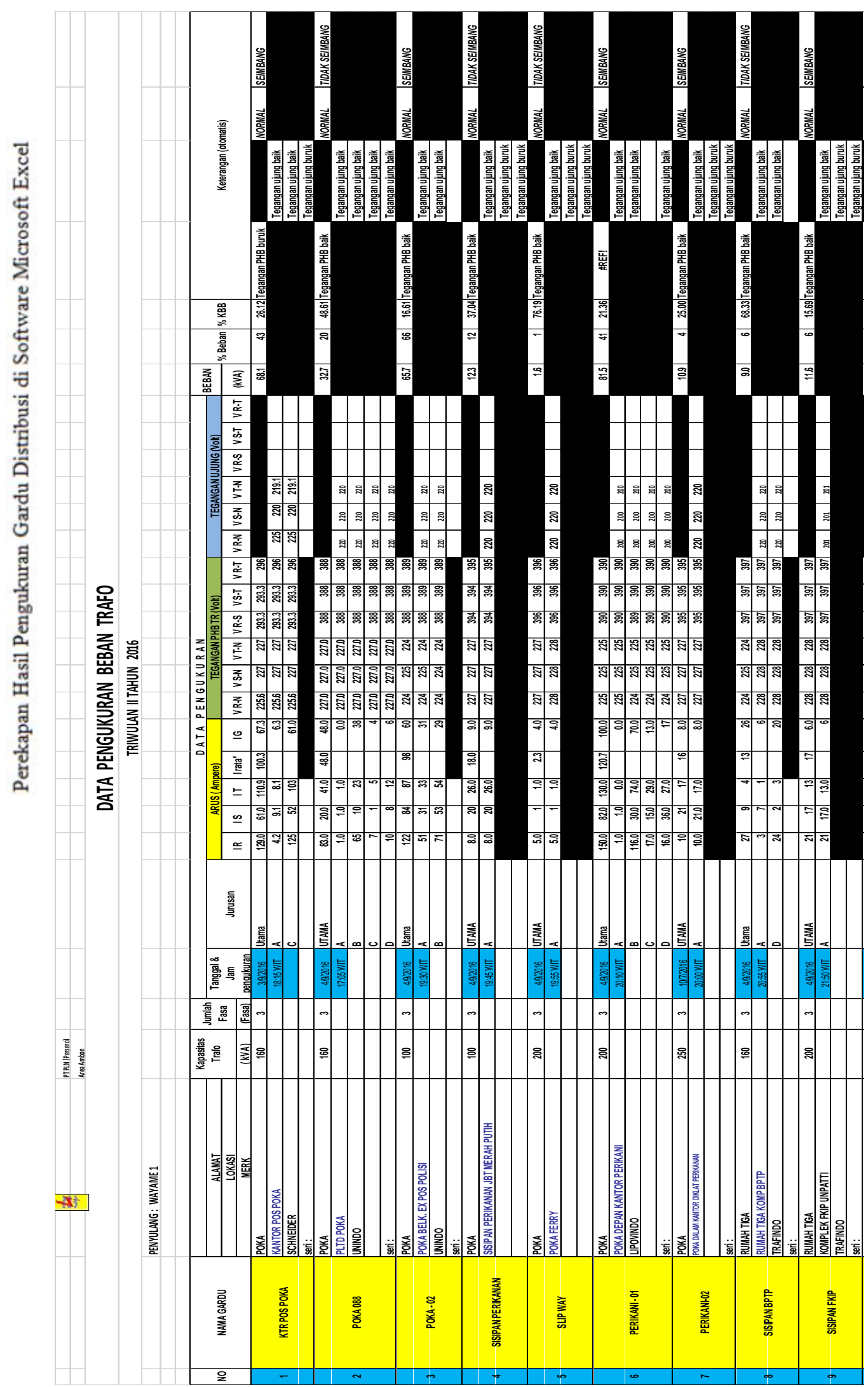




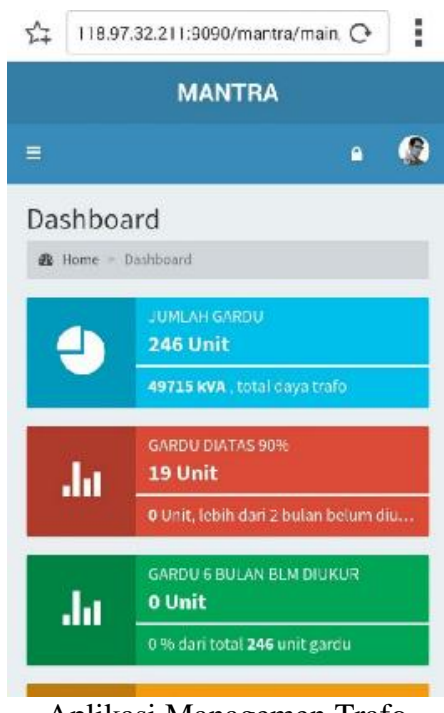

Aplikasi Managemen Trafo

5. Setelah data pengukuran direkap, maka dilakukan evaluasi hasil pengukuran gardu distribusi untuk dilakukan upaya-upaya menjaga keandalan seperti pemasangan trafo sisipan akibat kondisi beban lebih, penyeimbangan beban akibat beban di masing-masing fasa yang tidak seimbang, dan tindakan teknis lainnya.

\section{Perencanaan Produk}

Rencana proses dimulai dengan mengidentifikasi peluang - peluang pengembangan produk. Dalam hal ini sumber yang didapat adalah berdasar dari penelitian. Sehingga dari penelitian tersebut dapat diketahui kegagalan dan keluhan yang dialami oleh petugas.

Dalam melakukan pengukuran beban gardu distribusi, alat yang digunakan oleh petugas pelayanan teknik adalah tang ampere

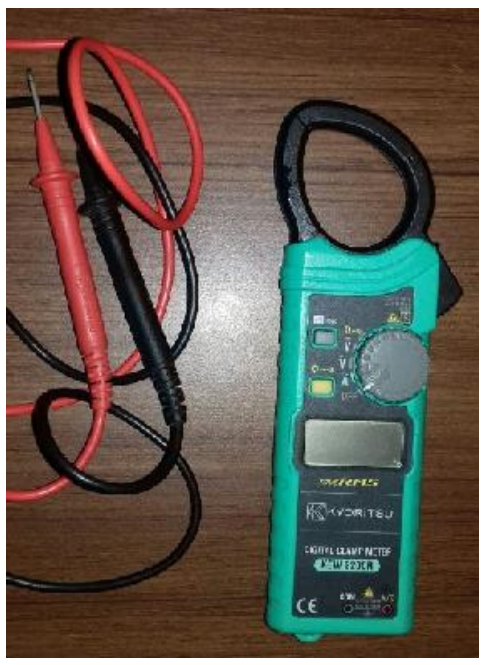

Tang Ampere

\section{Pengembangan Konsep}

Setelah dilakukukan penelitian maka perlu dilakukan identifikasi kebutuhan pelanggan dengan membuat kuisioner. Responden berjumlah 37 petugas , diambil dari 48 petugas yantek karena diangap sudah mencukupi untuk mewakili jumlah keseluruhan petugas yantek. Pengetahuan responden pada aspek teknis yang menyangkut pengukuran gardu dinilai sama karena seluruh petugas yantek telah mendapat sertifikasi, pelatihan dan tugas rutin yang berkaitan dengan pengukuran gardu sehingga pengetahuan yang didapat merata. Setelah dilakukan perekapan maka hasilnya adalah sebagai berikut. 

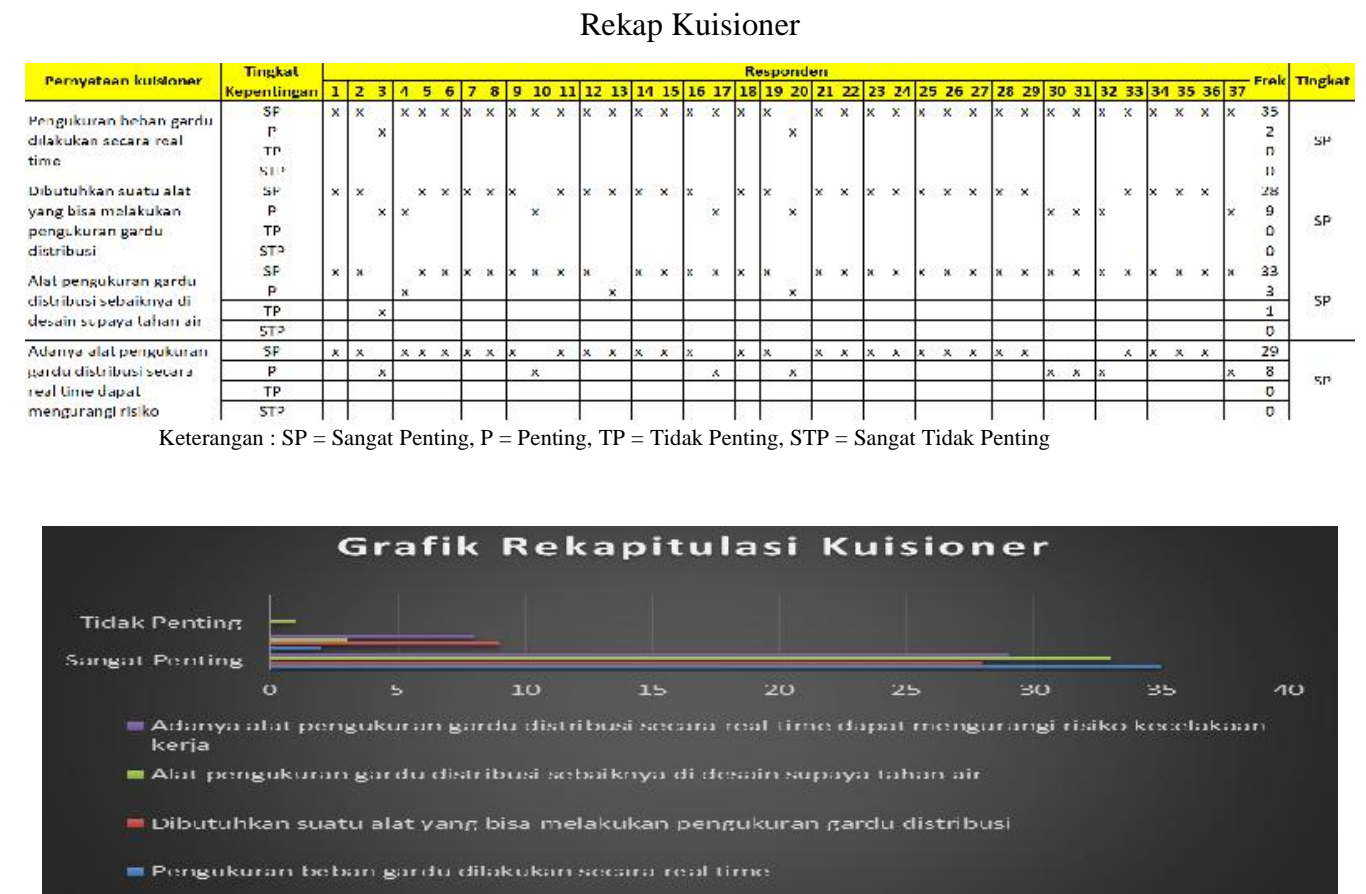

Grafik Rekapitulasi Kuisioner

Daftar Kebutuhan User

\begin{tabular}{c|l|c|}
\hline No & \multicolumn{1}{|c|}{ Kebutuhan } & Kepentingan \\
\hline 1 & Pengukuran dapat diakses sesuai keinginan user & SP \\
\hline 2 & Mengurangi risiko kecelakaan kerja & $\mathrm{P}$ \\
\hline 3 & Alat dapat bekerja di saat kondisi hujan & $\mathrm{P}$ \\
\hline \multicolumn{2}{|l|}{ Keterangan : SP = Sangat Penting, P = Penting, TP = Tidak Penting, STP = Sangat Tidak Penting }
\end{tabular}

Perencanaan Kebutuhan User

\begin{tabular}{c|l|l|}
\hline No & \multicolumn{1}{|c|}{ Kebutuhan } & \multicolumn{1}{|c|}{ Perencanaan } \\
\hline 1 & Waktu akses pengukuran & Membuat alat monitoring secara real time \\
\hline 2 & Mengurangi risiko kecelakaan kerja & Mengubah pola kerja \\
\hline 3 & Alat dapat bekerja di saat kondisi hujan & Melatakkan alat yang tepat \\
\hline
\end{tabular}

\section{Perancangan Tingkatan Sistem}

Dalam fase ini mencakup arsitektur produk/alat dan gambaran rakitan akhir untuk produk/alat ini. Untuk perancangan awal maka dibutuhkan bagian-bagian dari setiap komponen di dalam alat monitoring gardu distribusi secara real time.

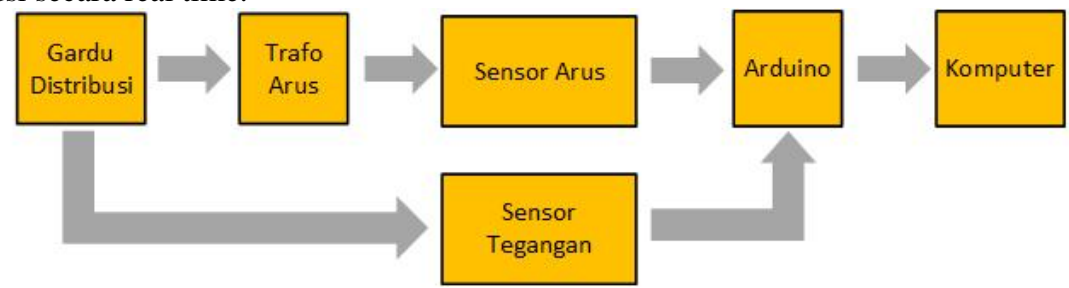

Blok Diagram Perancangan Alat Monitoring Beban Gardu Distribusi

Secara garis besar sistem akusisi sinyal listrik untuk monitoring arus dan tegangan listrik dapat dilihat seperti pada gambar diatas. Dari blok diagram pada gambar diatas, maka dari setiap bagiannya dapat diterjemahkan menjadi gambaran rakitan akhir seperti berikut 


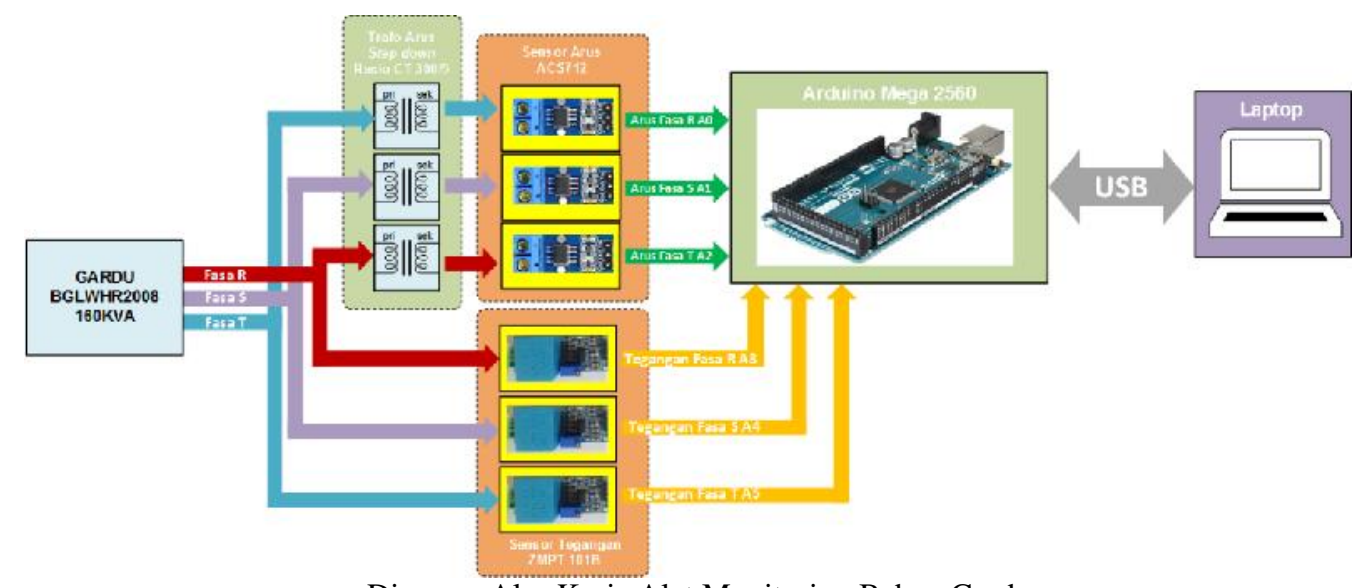

Diagram Alur Kerja Alat Monitoring Beban Gardu

\section{Perancangan Detail}

1. Prinsip Kerja Alat Monitoring yang Terhubung dengan Gardu BGLWHR2008

Gardu distribusi BGLWHR2008 memiliki kapasitas sebsar 160.000 VA, dengan 3 fasa. Masingmasing fasa untuk arus terhubung dengan trafo arus dan tegangan masing-masing fasa terhubung dengan sensor tegangan. Tiga buah trafo arus akan menurunkan arus pada masing-masing fasa pada sisis primer dan keluarannya pada sisi sekunder dengan rasio CT adalah 300/5.

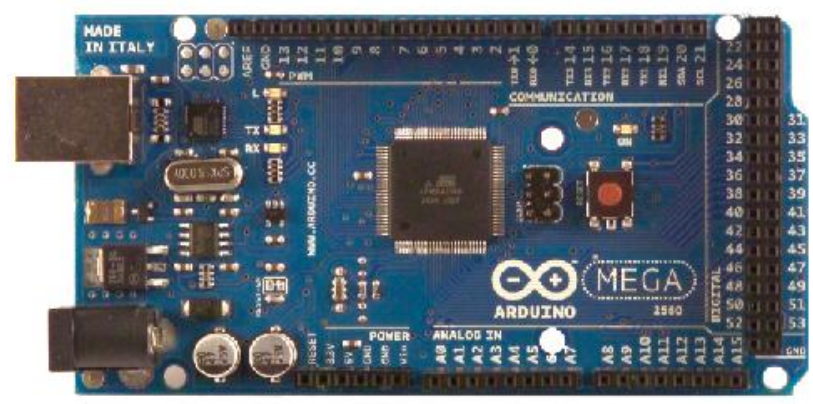

Arduino Mega 2560

MATLAB adalah program yang akan menampilkan hasil pengukuran pada komputer sekaligus mengolah data yang dikirim oleh arduino. Data ketiga arus fasa tersebut akan di rata-ratakan untuk memperoleh arus rata-rata gardu 3 fasa, dan ketiga tegangan fasa juga dirata-ratakan untuk memperoleh tegangan gardu rata-rata.

\begin{tabular}{|l|l|}
\multicolumn{2}{|c|}{ Spesifikasi Teknik Arduino } \\
\hline Spesifikasi Teknik \\
\hline Microcontroller & ATmega2560 \\
\hline Operating Voltage & $5 \mathrm{~V}$ \\
\hline Input Voltage (recommended) & $7-12 \mathrm{~V}$ \\
\hline Input Voltage (limits) & $6-20 \mathrm{~V}$ \\
\hline Digital I/O Pins & 54 (of which 14 provide PWM output) \\
\hline Analog Input Pins & 16 \\
\hline DC Current per I/O Pin & $40 \mathrm{~mA}$ \\
\hline DC Current for 3.3V Pin & $50 \mathrm{~mA}$ \\
\hline Flash Memory & $256 \mathrm{~KB}$ of which 8 KB used by bootloader \\
\hline SRAM & $8 \mathrm{~KB}$ \\
\hline EEPROM & $4 \mathrm{~KB}$ \\
\hline Clock Speed & $16 \mathrm{MHz}$ \\
\hline
\end{tabular}

2. Kalibrasi sensor arus ACS712 dan sensor tegangan ZMPT101B

Kalibrasi sensor sangat diperlukan karena keluaran sensor belum menunjukkan nilai variabel fisis yang sebenarnya. Data sheet Sensor arus ACS712 telah menampilkan grafik kalibrasi atau grafik keluaran 
sensor sebagai perubahan arus, sedangkan sensor tegangan ZMPT101B perlu dilakukan kalibrasi untuk melihat karakteristi sensor dan menghasilkan keluaran sensor sebagai perubahan tegangan AC.

3. Kalibrasi sensor ACS712

Berdasarkan datasheet sensor ACS712, persamaan keluaran sensor sebagai perubahan arus mengikuti persamaan: Vout $=0,194 \times I p-2,5$. Persamaan tersebut digunakan digunakan dalam pemograman untuk menampilkan nilai arus yang sebenarnya.

Spesifikasi Teknik ACS712

\begin{tabular}{|c|c|c|c|c|}
\hline Characteristic & Symbol & Note & Rating & Units \\
\hline Supply Voltage & $\mathrm{V}_{\mathrm{C}}$ & & 8 & V \\
\hline Reverse Supply Voltage & $\mathrm{V}_{\mathrm{RC}}$ & & -0.1 & $\mathrm{~V}$ \\
\hline Output Voltage & VIOUT & & 8 & $\mathrm{~V}$ \\
\hline Reverse Output Voltage & VRIOUT & & -0.1 & $\mathrm{~V}$ \\
\hline Output Current Source & IIOUT(Sou & & 3 & $\mathrm{~mA}$ \\
\hline Output Current Sink & IIOUT(Sin & & 10 & $\mathrm{~mA}$ \\
\hline Overcurrent Transient Tolerance & IP & 1 pulse, $100 \mathrm{~ms}$ & 100 & A \\
\hline Nominal Operating Ambient & $\mathrm{T}$ & Range E & -40 to 85 & ${ }^{\circ} \mathrm{C}$ \\
\hline Maximum Junction Temperature & TJ(max) & & 165 & ${ }^{\circ} \mathrm{C}$ \\
\hline Storage Temperature & $\mathrm{T}_{\mathrm{St}}$ & & -65 to 170 & ${ }^{\circ} \mathrm{C}$ \\
\hline
\end{tabular}

\section{Kalibrasi Sensor ZMPT101B}

Kalibrasi sensor tegangan ZMPT101B, dilakukan sesuai gambar 3.3. Terdapat tiga buah voltmeter yaitu voltmeter 1 (V1) digunakan untuk mengukur keluaran sensor 1, voltmeter 2 (V2) digunakan untuk mengukur keluaran sensor 2, voltmeter 3 (V3) digunakan untuk mengukur keluaran sensor 3 dan voltmeter 4 (V4) digunakan untuk mengukur tegangan lampu. Dimer lamp digunakan untuk mengatur banyaknya arus yang masuk ke lampu.

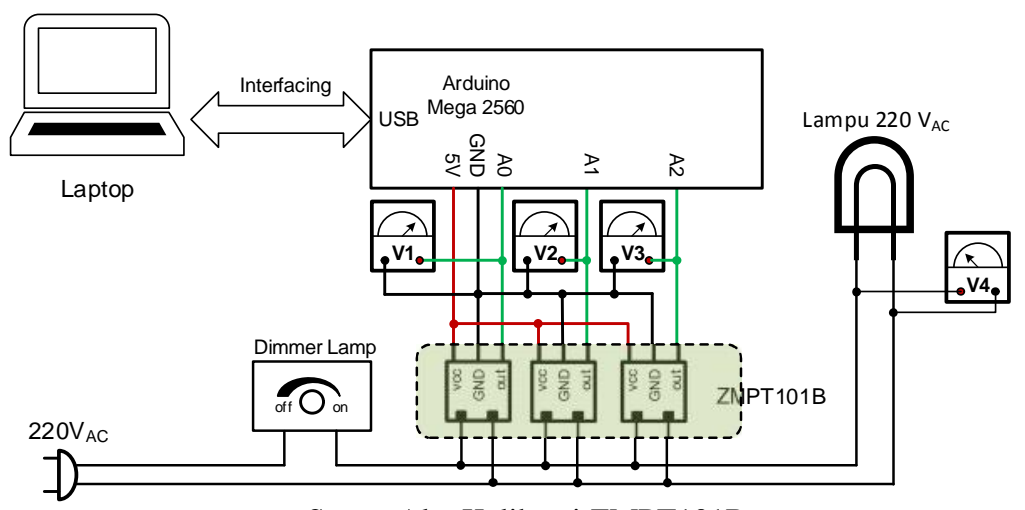

Set up Alat Kalibrasi ZMPT101B

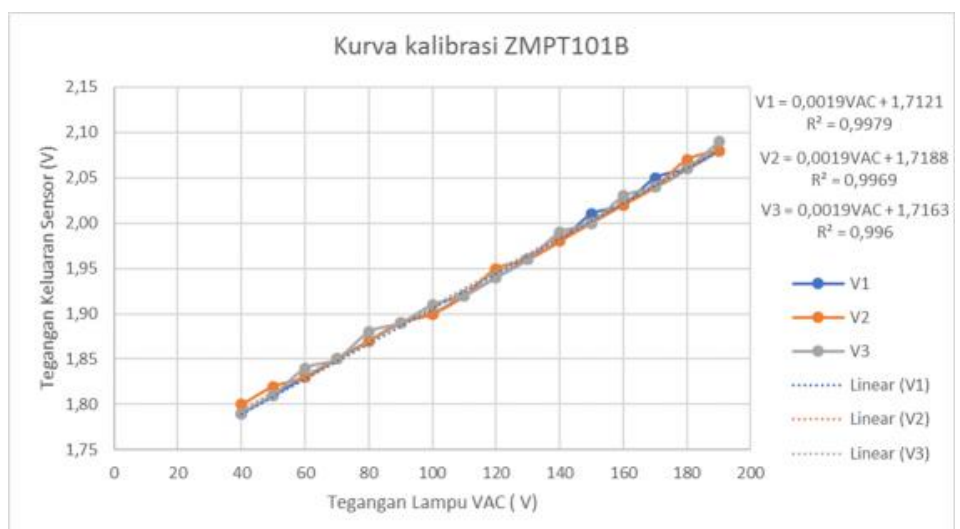

Grafik Kalibrasi Sensor ZMPT101B 
5. Diagram Alur Kerja Program Arduino dan MATLAB

Alat monitoring beban gardu secara real time melibatkan dua jenis program yang saling interaksi dalam proses akuisisi data. Program yang digunakan yaitu arduino digunakan untuk mengatur, mengendalikan kerja chip Atmega 2560, dalam melakukan pengukuran sekaligus mengirimkan hasil pengukuran ke komputer. GUI MATLAB digunakan sebagai bahasa pemograman untuk dapat berinteraksi dengan program arduino yang telah di upload dalam chip Atmega 2560 agar dapat menerima hasil pengukuran yang dikirmkan oleh arduino dan menampilkan hasil pengukuran pada layar komputer.

6. Diagram Alur Kerja Pemograman Mikrokontroller Menggunakan Arduino

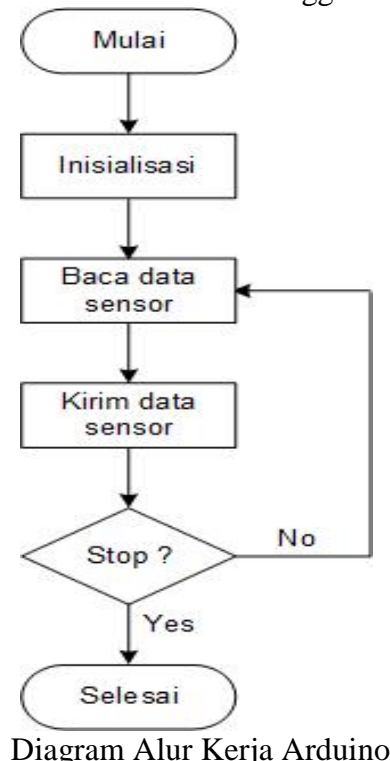

7. Diagram Alur Kerja Program GUI MATLAB

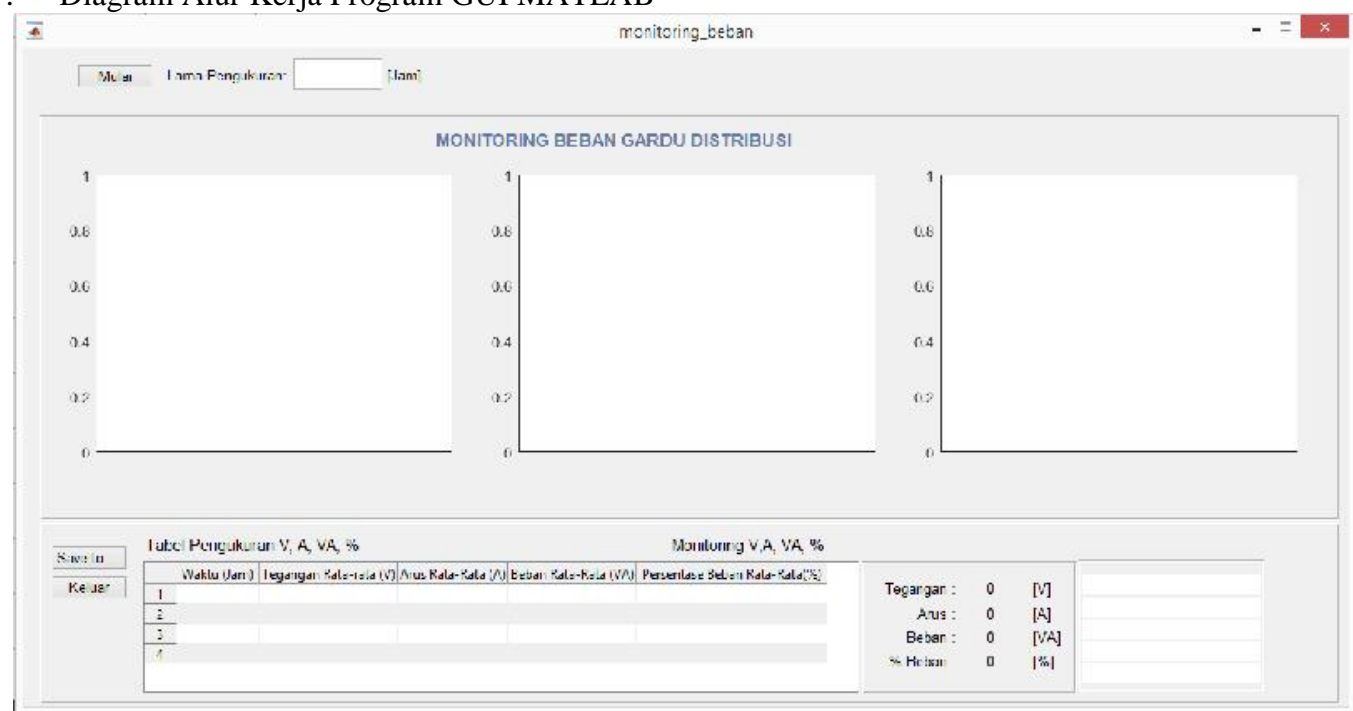

Tampilan GUI MATLAB Monitoring Beban Gardu

Perlu diketahui bahwa saat arduino terhubung dengan komputer, melalui USB maka secara otomatis komputer akan mendeteksi alamat port mana yang aktif. Berikut ini adalah diagram alur kerja program GUI MATLAB: 


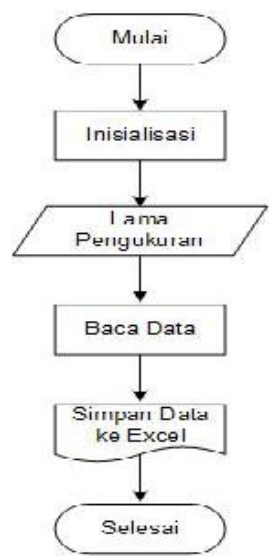

\section{Hasil Pengujian}

Diagram Alur Kerja GUI MATLAB

Hasil monitoring distribusi beban gardu rata-rata, persentase beban gardu rata-rata tiga fasa ditunjukkan pada tabel 4.3 dan digrafikkan sesuai gambar 4.13 dan 4.14. Lama pengukuran dilakukan selama 6 jam, dimulai dari pukul 17:00 - 23:00 dan pengambilan data dicuplik setiap 1 jam.

\begin{tabular}{|c|c|c|c|c|c|}
\hline Waktu (Jam) & Jam ke- & $\begin{array}{c}\text { Tegangan Rata-Rata } \\
3 \text { Fasa (V) }\end{array}$ & $\begin{array}{c}\text { Arus Rata-Rata } 3 \\
\text { Fasa (A) }\end{array}$ & $\begin{array}{c}\text { Beban Rata-rata } 3 \\
\text { Fasa (VA) }\end{array}$ & $\begin{array}{l}\text { Persentase Beban } \\
\text { Rata-Rata } 3 \text { Fasa (\%) }\end{array}$ \\
\hline $17: 00$ & 0 & 219,52 & 115,64 & 80117,23 & 50,07 \\
\hline $18: 00$ & 1 & 219,52 & 115,64 & 80117,23 & 50,07 \\
\hline $19: 00$ & 2 & 219,52 & 118,66 & 82211,80 & 51,38 \\
\hline $20: 00$ & 3 & 219,52 & 141,34 & 97921,06 & 61,20 \\
\hline $21: 00$ & 4 & 219,52 & 127,27 & 88173,26 & 55,11 \\
\hline $22: 00$ & 5 & 222,09 & 120,24 & 83307,41 & 52,07 \\
\hline $23: 00$ & 6 & 219,52 & 118,24 & 81921,77 & 51,20 \\
\hline
\end{tabular}

Data Pengukuran

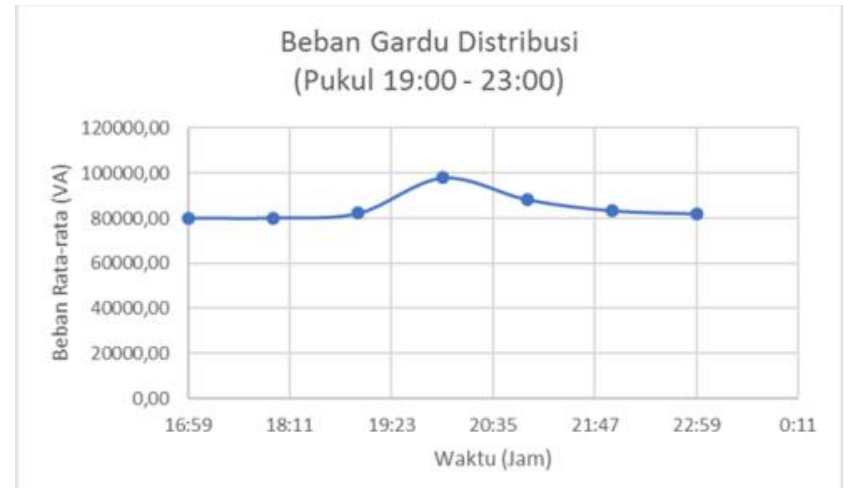

Grafik Hasil Monitoring Beban Gardu Distribusi

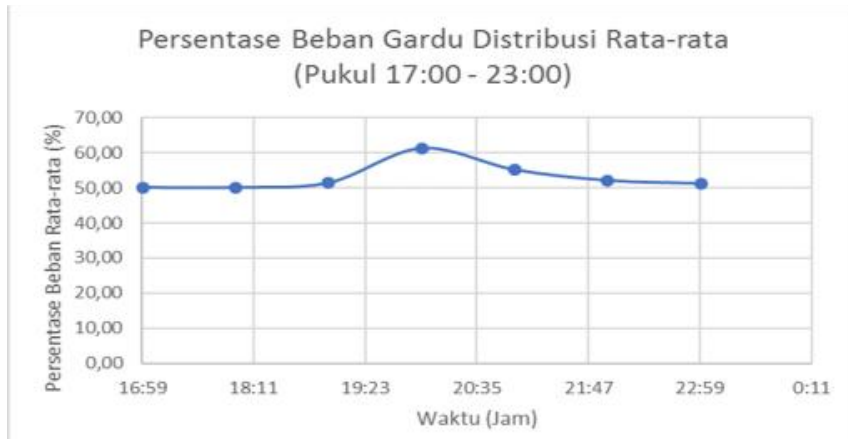

Grafik Hasil Monitoring Persentase Beban Gardu Distribusi 
Berdasarkan SPLN 1: 1995 tentang tegangan - tegangan standar no 9 hal 5 bahwa tegangan nominal $230 / 400 \mathrm{~V}$ memiliki variasi tegangan pelayanan $+5 \%-10 \%$. Sehingga untuk nilai tegangan yang tercantum masih dalam batas standar.

Pemakaian Beban Berdasarkan Pembagian Waktu

\begin{tabular}{|cccc|}
\hline Bagian Ke - & $\begin{array}{c}\text { Waktu Pemakaian } \\
\text { (Jam) }\end{array}$ & $\begin{array}{c}\text { Beban Rata-Rata } \\
\text { (VA) }\end{array}$ & $\begin{array}{c}\text { \%Beban Rata-Rata } \\
(\%)\end{array}$ \\
\hline 1,00 & Pukul: 17:00 - 19:00 & 80815,42 & 50,51 \\
\hline 2,00 & Pukul: 19:00 - 21:00 & 89435,37 & 55,90 \\
\hline 3,00 & Pukul: 21:00-23:00 & 84467,48 & 52,79 \\
\hline
\end{tabular}

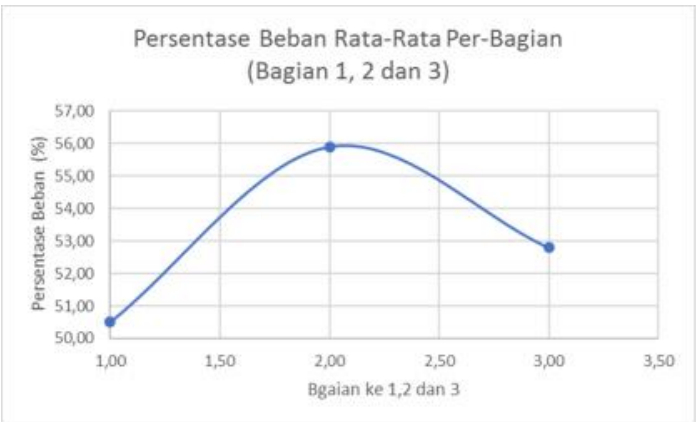

Grafik Persentase Beban Gardu Terhadap Pembagian Waktu

\section{KESIMPULAN}

Berdasarkan perancangan desain alat monitoring beban yang terdistribusi, maka dapat disimpulkan sebagai berikut:

1. Berdasar hasil identifikasi user maka sangatlah dibutuhkan alat monitoring beban gardu distribusi secara real time

2. Dengan menggunakan metode perancangan produk terkait perancangan monitoring beban gardu, alat monitoring dapat bekerja secara real time, menampilkan pengukuran arus rata-rata, tegangan tegangan rata-rata, beban hingga persentase beban secara kontiniu terhadap waktu yang dicuplik setiap 1 jam menggunakan GUI MATLAB.

3. Persentase beban rata-rata saat waktu puncak antara pukul 19:00 - 21:00 adalah 55,90\%, dan gardu BGLWHR2008 masih dalam kategori normal.

4. Terjadi peningkatan pemakaian beban dari bagian pertama (15:00 - 19:00) ke bagian kedua (19:00 00:00) yatiu sebesar 5,39 \% dan terjadi penurunan pemakaian beban dari bagian kedua (19:00 00:00) ke bagian ketiga (00:00 - 10:00) yaitu sebesar 3,10\%.

\section{DAFTAR PUSTAKA}

Anonim, (2017). Fully Integrated: Hall Effect Based Linear Current Sensor IC with 2.1 kVRMS Isolation and a Low Resistance Current Conductor. USA : Allegro Microsystem, LLC.

Bishop . O. (2011). Electronics Circuits and Systems. USA : Elsevier LTD.

Boylestad. Introductory Circuit Analysis . Tenth Edition.

Floyd. (2015). Digital Fundamentals. Eleventh Edition. USA : Pearson

Ginting, R. (2010). Perancangan produk.Universitas Sumatra Utara, Medan

Irvan, M. (2015). Fase Pengembangan Konsep Produk dalam Kegiatan Perancangan dan Pengembangan Produk. Faktor Exacta, 4(3), 261-274..

Kenny .T . (2005). Optical and Radiation Sensors Jon Wilson Sensor Technologi Handbook. USA : Elsevier Inc.

Michael. T. (2002). Electronic Circuits: Fundamentals and Applications. India : Newnes.

Ulrich Karl T, Eppinger, Steven D. (2001). Perancangan Pengembangan Produk . Jakarta : Salemba Teknika. 
